\title{
Alternativo
}

\section{PERSPECTIVAS DE ECOTURISMO PARA O BOQUEIRÃO DE LAVRAS DA MANGABEIRA - CE}

\author{
Victor Emídio Campos (1) \\ Cícera Cecília Esmeraldo Alves (2) \\ Thalita Ferreira Campos (3)
}

\begin{abstract}
Resumo
O trabalho foi idealizado levando-se em consideração as tendências ecoturísticas para o Boqueirão de Lavras da Mangabeira, através de análise de bens naturais, com que se abordam as relações socioculturais, poder administrativo e meio ambiente. Visualiza, outrossim, além de a "atividade turística ser exercida com qualidade, competência e total dinamismo vinculado às necessidades e exigências do mundo moderno", com base nas observações in loco, a população do entorno, influências antrópicas, animais ameaçados de extinção, queimadas e cortes de madeira desordenados, assoreamento das margens do Rio Salgado, a fim de proporcionar projetos de pesquisa de iniciação científica. Os resultados mostram como se relacionam os visitantes, estudantes e habitantes da localidade, através de entrevistas formais e informais, durante os seis (06) anos de pesquisa de campo e estudos das produções didáticas. Por outro lado, o resultado consignou, em primeiro lugar, a alternância de insatisfações, diante do que as autoridades pregam e o que é legalmente constituído, pois os agentes se julgam capacitados a resolver o problema, mas neutralizam, na sua delimitação, quando se requer agilidade dos fatos. Em segundo, a experiência obteve resultados satisfatórios quanto à demanda: a população reivindica a Área de Proteção Ambiental para o Boqueirão, por ser indispensável à sua preservação, vez que pode haver perca irrecuperável no ecossistema, se não se providenciarem política de conservação/preservação.
\end{abstract}

Palavras-chave: Ecossistema. Meio Ambiente. Biodiversidade.

\section{Introdução}

A pesquisa foi viabilizada, por meio de canais formais e informais a "perspectiva de ecoturismo para o boqueirão de Lavras da Mangabeira”, mediante análise da oferta de produtos obtidos, a partir de contatos com populares. Objetivou trabalhar a biodiversidade sustentável, utilizando-se o sociocultural, coleta e causa à população do entorno sobre influência antrópica, animais ameaçados de extinção, caça e pesca predatórias com fins financeiros, queimadas e cortes de madeira desordenados, assoreamento das margens do Rio Salgado, depoimentos dentro de perspectiva econômica moderna, a fim de proporcionar projetos de pesquisa de iniciação científica.

A finalidade do estudo foi embasar uma proposta às autoridades do desenvolvimento sustentável, através de alternativas econômicas que o empreendimento ecológico - ecoturismo - possa proporcionar ao povo da Região Centro-Sul do Estado, haja vista a passividade com relação à concretização da Unidade de 
Conservação Ambiental do Boqueirão, pois tendem as autoridades não intervir nas relações dos componentes da localidade, suspeitando perca subsequente.

Diante das interações pertinentes à sustentabilidade, inquieta-nos o seguinte: a comunidade tem-se dado conta da importância da transformação do Boqueirão em Unidade de Conservação Ambiental? Os contatos presenciais atestam que sim, enquanto que, na prática, através das autoridades de direito, se observa contradição ao que foi apurado na pesquisa.

A proposta visa levar a reflexão os objetivos trabalhados e despertar a criticidade da população com relação aos bens detectados, uma vez que o Boqueirão de Lavras tem sido um laboratório natural, que deve ser zelosamente preservado, onde se entrelaçam demandas sócio-ambientalista-culturais, sendo necessário expô-las para que as inquietações, discordâncias e concordâncias possam vir à tona.

Em termos metodológicos o presente estudo constou de duas pesquisas: abordagem bibliográfica e trabalho de campo. A primeira direcionou o embasamento teórico, ou seja, o levantamento bibliográfico, trabalhos monográficos, literatura de cordel, fichamentos de livros de autores que lidam com as temáticas em voga. Enquanto que, para a realização do trabalho de campo, entre algumas entidades civis, foi ouvida a comunidade, através da história de vida e da elaboração de um questionário direcionado a professores, alunos e populares residentes no município.

A amostra constou de uma faixa conceitual de 23,62\% (444) de um universo de 1.879 (mil, oitocentos e setenta e nove) participantes, os quais se envolveram na pesquisa, além da comunidades em geral, estudantes da rede pública e particular do ensino fundamental e médio de Lavras da Mangabeira. Enquanto que os resultados também deram conta de que temos, realmente, muito que melhorar com relação ao acolhimento e interação na localidade Boqueirão, pois as autoridades não parecem estar promovendo a preservação do patrimônio natural, embora esteja sendo cogitado, através de movimentos populares, construir soluções para amenizar mudanças climáticas e dar melhor qualidade de vida econômica e social às presentes e futuras gerações.

Acreditamos que, o homem, ao intervir no sistema ambiental, deve ter real conhecimento da estabilidade e da sensibilidade desse sistema. Por isso, dedicamos este estudo a todos os que voltaram suas vistas, tanto para o passado, quanto o presente e o futuro de Lavras da Mangabeira.

\section{Contexto sócio-histórico do município}

Situada na zona interiorana, a sub-bacia hidrográfica do Salgado, uma das 11 (onze) macrorregiões localizada no Sul do Estado do Ceará, Centro Norte da Região do Cariri, Lavras da Mangabeira, de relevo constituído por depressões sertanejas, com solo bruno não cálcico, podzólico, vermelho-amarelo litólico, compacto e raso, em parte coberto por seixos rolados, com capins e leguminosas no inverno, tendo arbustos distanciados, vegetação predominante de caatinga arbustiva aberta, caatinga arbustiva densa, floresta caducifólia espinhosa e floresta mista dicólito-palmácea, inclui-se dentre as belezas naturais do Estado do Ceará (PAIVA, 2008).

A população estimada do município em 2006 foi de 15.743 homens e 15.794 mulheres, possuindo iluminação e saneamento básico ainda insuficiente ao nível desejado. Área de $947,957 \mathrm{~km}^{2}$; e 866,4 mm de 
pluviosidade média anual. Clima tropical quente semiárido brando e tropical quente, semiárido: salubre e seco. A sede fica a 428 km de Fortaleza, via BR 116/230, então 335 em linha reta, com altitude de 239m acima do nível do mar. Apresenta coordenadas geográficas de $6^{\circ} 45^{\prime} 12^{\prime \prime}$ S de latitude e $38^{\circ} 58^{\prime} 18^{\prime \prime} \mathrm{W}$ de longitude, temperatura média variável entre $26^{\circ} \mathrm{C}$ e $28^{\circ} \mathrm{C}$ (LIMA, 1998 e PAIVA, 2008).

Segundo referencial colhido no link www.ceara.br, acesso em 19-03-2010), a economia estimada para o PIB (2005) foi de: R\$ 60845 000; agropecuária: 17,48\%; indústria: 12,29\%; serviços: 70,23\%; receita orçamentária (2007): R\$ 23525 101,25. Educação: taxa de alfabetização (2000): 66,5\%; escolarização no ensino fundamental (2007) e médio, respectivamente: $93,9 \%$ e $62,8 \%$. No quadro político, o município conta com (2006) 23670 eleitores, perfil masculino 11565 e 12086 feminino, 19 não informados.

\section{Características geoambientais}

Lavras da Mangabeira está incluída na Área de Proteção Ambiental - APA, unidade que recebeu proteção especial, através do governo federal, decreto da Presidência da República, em 5 de agosto de 1997. Com características geoambientais a qual conta com uma biodiversidade considerável.

O município é contemplado pelas águas do Rio Salgado. Em sua trajetória, absorvem os "detritos" da Região Metropolitana Caririense e de suas adjacências, passando pelo estreito Boqueirão, reconhecidamente como sendo uma entre as sete belezas naturais do Ceará. Estimativa expressa por estudiosos e pesquisadores da região aponta que mais de $80 \%$ dos dejetos poluentes estão sendo lançados diretamente no leito do rio, sem nenhuma preocupação ambiental.

No município existem diversidades culturais, fonte de emprego e renda que se prestam à exploração econômica para a localidade. Além do distinto comércio e indústria de beneficiamento, há um quadro bastante elevado de funcionários públicos: municipal, estadual e federal. Veem-se agências do Banco do Brasil, Banco do Nordeste do Brasil, postos do Bradesco e Caixa Econômica Federal; assentamento populacional e áreas rurais destinadas à preservação ambiental, engenhos de rapadura: ativados e desativados; cultura frutífera e leguminosa: mamão, banana, arroz, feijão; uma boa cifra de escolas públicas e particulares; barragens: Rosário, Três Irmãos, Extrema, entre várias outras de relevância, e abastecimentos consideráveis.

\section{Perspectivas do turismo para Lavras da Mangabeira}

O turismo e o desenvolvimento sustentável vêm se expandindo, após a Segunda Grande Guerra Mundial, devido ao avanço e a inovação tecnológica, nos meios de comunicação, vez que parte do princípio de que o ser humano deve satisfazer às necessidades, sem comprometimento das futuras gerações. Neste sentido, por um lado, Ferreira (2001) sugere o turismo como a realização de viagem ou excursão feita, "por prazer, a locais que despertam interesse" comum, a fim de que os recursos naturais racionalmente utilizáveis sejam apreciados.

Enquanto que, por outro, o turismo trata de atividade socioeconômica que na concepção comum aborda o tema, no sentido de satisfazer às necessidades das pessoas envolvidas. Donde Lage e Milone, (2000, 
pág. 26) enfatizam o turismo como "a ciência, a arte e a atividade de atrair, transportar e alojar visitantes", com o objetivo de satisfazer a necessidades e desejos particulares:

Do ponto de vista ambiental, com relação ao desenvolvimento sustentável, é evidente que o turismo é um grande negócio. [...] É óbvio, se pretendemos que o nosso setor continue crescendo, não devemos acabar com esta matéria-prima ou não vamos ter toda essa perspectiva de geração de riqueza e de emprego (LAGE e MILONE, 2000, p. 85).

Evidentemente, o turismo aparece atualmente como uma das atividades econômicas mais rentáveis, no cenário brasileiro, onde se destaca o segmento do ecoturismo, com probabilidade de $10 \%$ das viagens serem realizadas por americanos e europeus (Portal Educação e Sites Associados, 2010, p. 101). Este, por sua vez, torna-se uma atividade que tem relação direta com o desenvolvimento sustentável, haja vista que ele tem interdependência com os setores ambientais, sociais e culturais, objetivando a preservação dos recursos naturais e culturais, com vistas a garantir a sustentabilidade da comunidade local (CAMPOS, 2005).

O potencial turístico da região tem relevância considerável e vem se expandindo em todo o planeta como atividade promissora para o desenvolvimento sustentável do país: Aproximadamente 50 milhões de pessoas no mundo e meio milhão no Brasil praticam o ecoturismo. O crescimento anual estimado é de $20 \%$ no mundo e $10 \%$ no Brasil. As viagens voltadas à natureza representam 10\% das viagens de americanos e europeus; a primeira intenção de viagem para os turistas que vão à Costa Rica e ao Quênia. De 4 a 6 milhões de moradores dos Estados Unidos fazem, por ano, turismo na natureza fora de seu país; no Brasil, existem cerca de 250 operadores e agentes especializados e mais de 2000 meios de hospedagem, sendo aproximadamente 220 ecohotéis (Portal Educação e Sites Associados, 2010, P. 101).

Os mais preocupados com o desenvolvimento sustentável veem com bons olhos a utilização dos recursos naturais racionalmente utilizáveis, que servem para atender às necessidades humana, tanto do ponto de vista da geração presente, sem prejudicar o meio ambiente, como das gerações futuras. Desta forma, a "participação do Brasil no mercado do ecoturismo ainda é muito pequena, considerando-se que o país tem potencial para desenvolver vários segmentos do turismo na natureza” (Ibidem).

Pode-se perceber com a reflexão que o

[...] desenvolvimento sustentável é o tipo de desenvolvimento que pode se buscar no ecoturismo, pois são conceitos correlatos, visto que a definição e o fim de ambos estão interligados, propiciando desde então mecanismos para o desenvolvimento das comunidades. Esses mecanismos seriam as estratégias e planos elaborados pelos empresários e governos, baseados na sustentabilidade e conservação utilizados no ecoturismo (Idem).

Assim sendo, tem por objetivo a participação das comunidades no processo, causando o desenvolvimento sustentável para todos os envolvidos. A posição dos países em desenvolvimento tornou-se mais estruturada, e o ambiente político internacional também favoreceu a aceitação pelos países desenvolvidos. A mudança de concepção com relação à complexidade do tema deu-se, de forma muito clara, nas negociações diplomáticas, apesar de o impacto ter sido menos do ponto de vista da opinião pública. 
Os compromissos da sustentabilidade precisam ser debatidos e deliberados por todas as esferas sociais, com participação de todos os interessados e afetados, colocando-se como planejamento participativo que avance para um novo paradigma de desenvolvimento. Uma frase que virou jargão da sustentabilidade: "pensar global e agir local" pode dar uma boa pista de como implantar ações que integrem na superação desses desafios.

Através da pesquisa de campo, indagou-se a população sobre o atendimento dispensado na localidade Boqueirão, tendo o estudo comprovado que existe realmente muito o que melhorar ali diante os administradores, pois dos visitantes e populares indagados, $57 \%$ responderam que o acolhimento não está sendo tão favorável como deveria ser (Média entre Ótima/Boa), sendo necessário rever algumas questões para funcionar da forma adequada. Já 23\% afirmaram estarem abaixo da média estipulada na pesquisa (Média entre Regular/Péssimo), devendo ser trabalhado de forma inteligente o acolhimento, uma vez que a situação anda desordenada. E $20 \%$ não se manifestaram.

Lage e Milone (2000) acrescentam, nesse sentido, que uma cidade só será boa para o turista, se for boa para o cidadão que nela vive:

Saibamos receber os nossos visitantes com profissionalismo, competência, qualidade e diferenciais. Já não é suficiente que o turista retorne a sua casa apenas com a lembrança de que visitou uma terra de belezas e riquezas admiráveis. É preciso também que ele verifique, com a sua própria experiência, a competitividade que os brasileiros têm sido capazes de criar e organizar em produtos a partir destas belezas e destas riquezas (p. 15).

Entretanto, o principal problema identificado é a ausência de dinâmicas que assegurem a participação efetiva dos atores sociais interessados pela questão, onde se denota ainda o desinteresse pela participação em tomadas de decisão sobre questões sociais e, quando há o interesse, há sempre muitas dificuldades de efetiva participação.

\section{Demanda ecoturística}

A demanda ecoturística em Lavras pode ser entendida como a quantidade de bens e serviços turísticos, visto que os consumidores desejam e estão dispostos sempre a adquirir, por um preço relativamente aceitável, pois os indivíduos se inteiram desses produtos, à medida que o preço também esteja equiparado às suas condições financeiras, vez que a lei de mercado anuncia que o custo da mercadoria aumenta inversamente proporcional à aquisição de produto, porque as pessoas tendem a consumir menos produtos se a eles não forem disponibilizados. "Em termos gerais, tem-se que a demanda em turismo é um composto de bens e serviços, e não demanda de simples elementos ou de serviços específicos isoladamente, ou seja, são demandados bens e serviços que se complementam entre si” (ROCHA, 2004, P.51).

Inicialmente, chama-se a atenção dos defensores da natureza para refletir e despertar sobre a problemática impactante do ecoturismo; para isso, dois aspectos devem ser considerados preventivamente: primeiro, a maior parte dos ecossistemas deve ser mantida sem qualquer distúrbio. E como segundo, a evidência dos impactos não seja notada pelos visitantes; portanto, o primeiro aspecto associa-se à proteção da área, enquanto que o segundo trata da proteção da qualidade da experiência dos visitantes; no entanto, ambos são importantes, mas a questão central consiste na manutenção da integridade dos ecossistemas. 
Todo sistema de procura deve ser monitorado pelos agentes do desenvolvimento sustentável, para permitir a sistematização da coleta e registro de dados, de forma contínua e confiável, sendo um instrumento que possibilite a identificação de problemas potenciais ou efetivos relacionados à visitação. Esse monitoramento também serve para tabulação do que foi detectado, a fim de orientar o que se deve acompanhar, onde, quando e por quem, no sentido de ser complementado, quando necessário, por diversos meios que auxiliam a coleta e registro dos elementos.

Segundo a WWF-Brasil, 2003, p. 319/320 (Portal Educação e Sites Associados, 2010), o desenvolvimento sustentável de um monitoramento e controle de impactos de visitação (MIV), no nosso caso, a área pleiteada, envolve, pelo menos, a realização de 10 passos a saber: 1 Montar equipe multidisciplinar, de acordo com as características levantadas no planejamento e mapeamento;2 Revisar a legislação e as políticas ambientais e de turismo relevantes para a UC (Unidade de Conservação) ou propriedades envolvidas; 3 Analisar ou elaborar objetivos gerais para o uso da área protegida ou propriedade, objetivos específicos para a atividade de "ecoturismo" e definir objetivos específicos por trilha ou local de visitação;4 Determinar indicadores para monitoramento de cada área;5 Determinar parâmetros de impactos aceitáveis para cada indicador, incluindo as unidades de medida;6 Determinar a capacidade de carga suportável;7 Elaborar a Matriz de Monitoramento, incluindo os instrumentos de coleta e compilação de dados;8 Coletar dados iniciais para o monitoramento de todos os indicadores, ajustar os instrumentos de coleta e compilação de dados e realizar a primeira etapa de treinamento dos responsáveis pelo mapeamento e manejo;9 Analisar os usos conflituosos ou excessivos observados, durante a coleta de dados iniciais, para o monitoramento e determinar ações de manejo corretivas; e10 Treinar os responsáveis para implementar o MIV.

Tendo em vista os passos sugeridos, cumpre unir esforços para buscar apoio à oferta e demanda do ecoturismo para o município. Costa (2006) argumenta que:

a cultura representa um fator primordial no processo de desenvolvimento local e regional sustentável, não somente por contribuir para estimular o sentimento de identidade regional, mas também por aumentar a autoestima das comunidades; acumular capital social; assegurar o comprometimento das pessoas com projetos de desenvolvimento e gerar oportunidades de emprego e renda (Cultura e Integração Regional: Pedro Brito, Ministro da Integração Nacional, p. 10).

Neta perspectiva, os sistemas enfocado na culminância de delinear algumas falhas, focaliza o processo de construção detectado no Plano de Ação, como boa integração dos órgãos municipais e assumem iniciativa promissora de articular cultura, meio ambiente e estratégias de desenvolvimento local para o próprio crescimento sócio-político e econômico da população.

Infelizmente, o município, através de seus gestores, ainda não despertou para um ponto que é bastante interessante, nas políticas públicas municipais: trabalhar, realmente, em conjunto, sem atacar ou querer denegrir, e muito menos, diminuir parceiros, mas inventariar e se completarem na busca do mesmo objetivo, beneficiar a todos inconsistentemente. Pois a competência não está só no querer, mas também no saber e querer fazer, visto que para isso é necessário apoio e condição financeira para tal fim. 


\section{A análise da demanda}

Continuando ainda dentro da demanda ecoturística para o município, um aspecto bastante fundamental deve ser evidenciado no planejamento: o seu conhecimento. A análise da demanda e de suas correlações com a oferta turística implica o conhecimento de sua estrutura, sua evolução e suas tendências futuras. A obtenção deste conhecimento independe, muitas vezes, de esquemas de investigação científica. Depende, sim, do saber acumulado (testemunho) por aqueles que trabalham ou moram, há muito tempo, na localidade.

Mais vale para o monitoramento do planejador buscar as informações necessárias ao conhecimento da demanda do que manter pesquisas complexas e caras de resultados limitados no espaço e no tempo. Contudo, em alguns casos, a inexistência de uma experiência turística leva à necessidade de partir do zero, na obtenção das informações requeridas; portanto, luta-se justamente na busca de aquisição de informações consistentes para a oferta pleiteada.

Um aspecto fundamental na análise da demanda é a sua segmentação. Portanto, "vários são os critérios" para definição dos segmentos do mercado. Um deles, considerado o principal, é o que divide a demanda em efetiva e potencial:

a) Demanda "efetiva" é aquela que já ocorre naturalmente, dentro dos esquemas atuais de oferta e procura turística.

b) Demanda potencial é a que ainda não ocorre efetivamente, mas poderá vir a ocorrer, se um ou mais fatores impeditivos forem eliminados: dificuldade de acesso, por exemplo.

Um terceiro aspecto relacionado aos dois anteriores é a inexistência de forma (serviços) turística; custo incompatível com o poder aquisitivo do consumidor; desconhecimento do produto por parte do aquisitor, entre outros.

A demanda, quanto à distância do mercado consumidor, é outro critério de relevância fundamental, mas não o principal. No entanto, para sua superação, pode-se falar em turismo local, feito pelos moradores da localidade e circunvizinhanças. A demanda incrementa o turismo regional, estadual, nacional e, por que não internacional: os "verdes mares bravios de sua terra natal". Quem diz essa célebre frase não são os que se desdobram na elaboração desta proposta, mas o próprio Túlio Monteiro (2002), quando vasculha o recôncavo interior do Ceará: na fádica localidade, onde mora uma artista de estranha e fina sensibilidade, que modela, numa arrebatação impressionante, as coisas naturais que aqui existem e que podemos explorar.

Após citar esses critérios, dá-se continuidade com um quarto, quanto ao nível de renda e consumo: turismo popular, social, convencional e de luxo, e fecha-se o alegado com o quinto aspecto que relaciona as motivações das viagens: aqui tem "solo amarelo ou vermelho, compacto e raso, em parte coberto por seixos rolados, com capins e leguminosas no inverno, tendo arbustos distanciados. [...] É atravessado pelo Rio Salgado, que passa por estreito boqueirão (...), uma das belezas naturais do Ceará” (PAIVA, 2008, p. 20).

O que é importante salientar para essa segmentação é a identificação de maior poder de demanda e adequação da oferta do município a que está vinculado. São muitas histórias que envolvem o município, algumas pitorescas, com variedades de graus de veracidade e mesmo de pura ficção, enriquecendo o folclore a seu respeito, envoltas em lendas e contos, vez por outra, cantadas em versos e que descreem sem reservas, as peraltices de Lavras, bem como a vida do Boqueirão. 
Os produtos ecoturísticos, decantados pelos poetas, decorrentes da localidade pleiteada neste trabalho, demonstram uma face do Boqueirão de Lavras, os ecoturistas: a população local e os visitantes relacionados com os bens naturais, a fauna e a flora. A outra provém das imposições e disposição levantadas, a partir das probabilidades históricas, diante de olhares de observadores mais atentos aos recursos naturais, pois a elaboração da obra parte da premissa de olhares que se cruzam. Trata-se de esquema unilateral; um olhar teleguiado, uns olhares bem móveis, vez por outra, se distinguem e se complementam. Devemos, então, ser atores participantes e ativos na transformação dos bens comuns à nossa população. No entanto, esse é que está sendo o grande problema: não "se trata de saber o que todo o mundo sabe, trata-se de 'como' saber e 'como' torná-lo operacional" (ALMEIDA, 2008, p. 160).

\section{Propostas de Ecoturismo Científico-Cultural para a localidade}

Com relação ao ecoturismo para a localidade os entrevistados se posicionaram da seguinte forma: se já conhece e se visitou o Boqueirão e o que motivou a se deslocar até a área pleiteada, 93\% indicaram-nos positivamente, bastante entusiasmados e, ainda, com a ideia de se produzir atividade ecológica para a referida localidade. Enquanto $6 \%$ se posicionaram negativamente. Apenas $1 \%$ não se manifestou: motivos não identificados.

Uma proposta de ecoturismo científico-cultural para o município de Lavras indica ser de relevância fundamental, porque foram levantados junto à população alguns questionamentos quando se busca atividades sustentáveis de desenvolvimento econômico. Os resultados, até então produzidos, dão aos indivíduos e às empresas que se dedicarem à produção de bens e à prestação de serviços, um número significativo de profissionais de vários setores, vez que boa perspectiva de vida, conotações relevantes para as atividades que se pleiteiam, entre estas, o deslocamentos de produtos, objetos de encontros emocionais, artísticos e de informação, nos diversos ramos da sociedade, são bastante viáveis.

Boqueirão, bem como outras localidades no município, dispõe de bens e argumentos naturais que, se disponibilizados for ao empreendimento ecológico, darão resultados incontestáveis. Como exemplo de bens, ecoturismo científico-cultural.

No entorno do Boqueirão, assunto abordado, em parte, anteriormente, existem inúmeras fontes que, planejadas, podem ser aproveitadas e utilizadas como objeto de estudo e pesquisa pelas comunidades escolares e acadêmicas da região. Há, portanto, possibilidade de recuperação desses bens de relevante valor paisagísticoscultural da nossa região.

Mais uma vez, foi abordada a população de Lavras, inclusive a da localidade pleiteada, a fim de obter se é do conhecimento de todos os fatos notáveis de extinção nas comunidades referente à "fauna e flora", bem como ocorridos na caverna do Boqueirão

Por conseguinte, a pesquisa de campo indicou-nos o seguinte cociente: $75 \%$ optaram por afirmar que são evidentes os fatos lendários naquela localidade. Como também $18 \%$ opuseram-se afirmando não ter conhecimento de tais evidências, e 7\% não quiseram optar, por motivos não referenciados.

$\mathrm{Na}$ visão de especialistas as motivações e estratégias que cercam o exercício do turismo cultural, pode ser subdividido em dois subtipos: turismo científico e turismo de congressos ou de convenções (ROCHA, 2004). O primeiro refere-se ao interesse ou às necessidades de relações compatíveis: estudos empíricos e pesquisas, no 
caso, o que vem se caracterizar pelos interesses pessoais dos visitantes para, com as fontes e objetos, buscar o que mais lhes interesse: objetos novos dentro da ciência, por sua própria natureza e pela finalidade do comportamento sistemático dos turistas no interior do núcleo receptivo que se encontra.

Dentre esse tipo de lazer, o repouso torna-se elemento secundário de produção e, não raro, é objeto a que os turistas se propõem. Portanto, o segundo tipo, o turismo de congresso ou turismo de convenções passa a ser entendido como o conjunto das atividades exercidas pelos indivíduos que viajam, a fim de participarem de eventos desta natureza: congressos, seminários, convenções, assembleias, simpósios, entre outros, que visam a estudos e alternativas de dimensões e interesses no campo científico. Então, para pensar localmente é preciso também pensar globalmente (ALMEIDA, 2008, p. 149). São iniciativas dessa forma que levam os municípios a se preocupar com ações sociopolíticas, ecológicas e planejamento.

O município tem muito a ser explorado através do ecoturismo, podendo ser colocado como exemplo: barragem com sua mata ciliar reconhecida por especialistas como a sétima beleza do Estado.

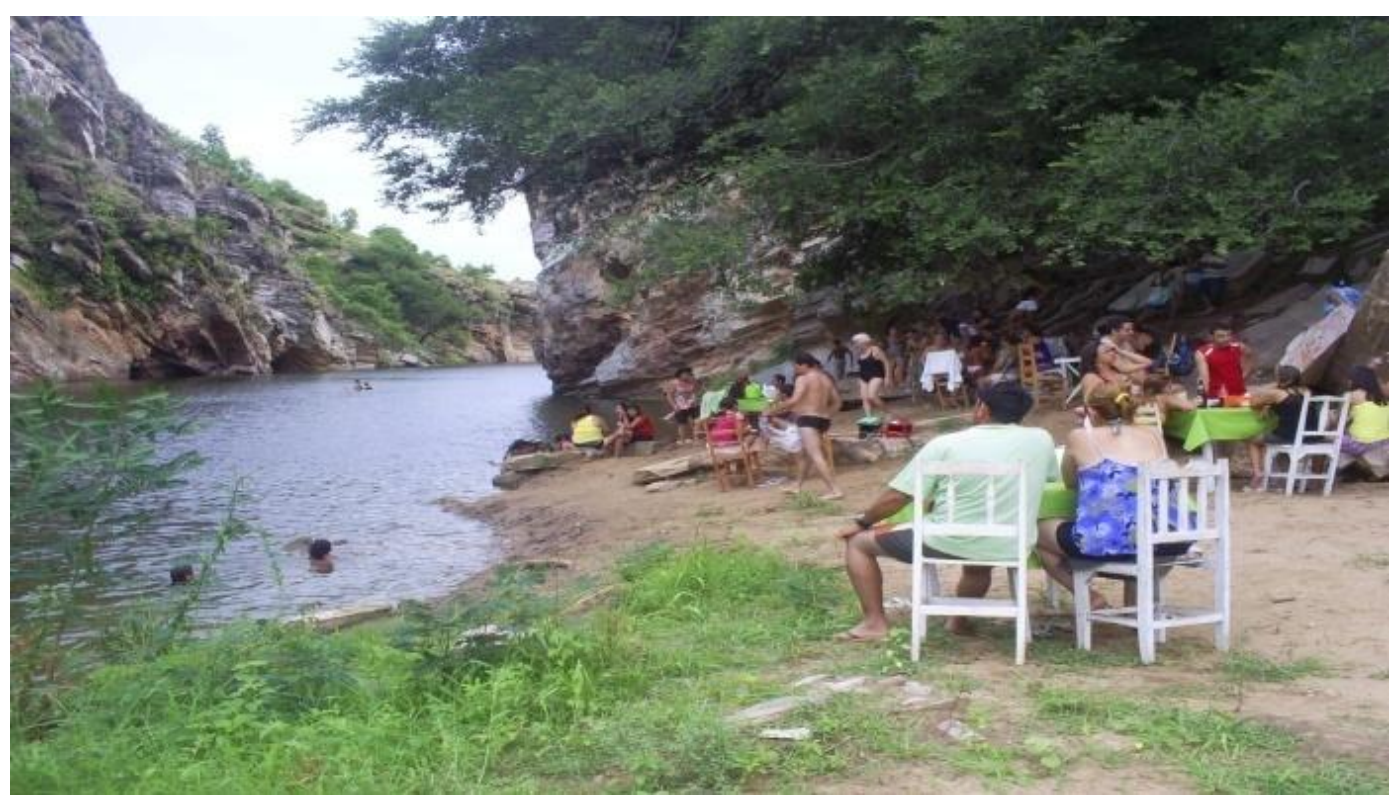

Figura 1: Local reservado a lazer e fonte de pesquisa culto-científica

Fonte: Dados da pesquisa de campo, 2009

De acordo com as estatísticas nacionais e internacionais, o turismo de congresso é um dos eventos de mais frequência, no mundo atual, e cria o maior número de oportunidades e garante o crescimento da demanda do turismo. Diante do exposto, indica-se o município de Lavras da Mangabeira, como boa alternativa para o turismo científico, pela existência de monumentos históricos tais como: "Gruta do Boqueirão" com suas lendas e mitos, fauna e flora características, beleza cênica.

\section{Propostas de Ecoturismo Religioso para o município}

Para promover uma "jornada espiritual" no País, a EMBRATUR divulga painéis retratando Igrejas de Salvador (BA), São Paulo (SP), Congonhas (MG) e Olinda (PE). Além desses, o principal roteiro de turismo religioso no Brasil: Aparecida do Norte-SP, que tem como símbolo o Santuário Nacional de Nossa Senhora da 
Conceição Aparecida, que recebe, em média, 9,5 milhões de romeiros anuais. Enquanto que no Ceará temos as romarias: de São Francisco das Chagas - Canindé-CE; Pe. Cícero - Juazeiro do Norte-CE; Santo Antônio Barbalha-CE e, em menor escala, São Raimundo Nonato - Várzea Alegre-CE e São Vicente Ferrer - Lavras da Mangabeira.

Essas festas foram criadas com o intuito de promover os destinos do segmento religioso das diferentes culturas em seus continentes. É, não resta dúvida, uma boa oportunidade para divulgar os produtos turísticos (artesanal) de peregrinação, abrigando, assim, um leque de descobertas sobre as variadas tradições religiosas, com viés em história, cultura e tecnologia aos interessados pelas progressivas inovações.

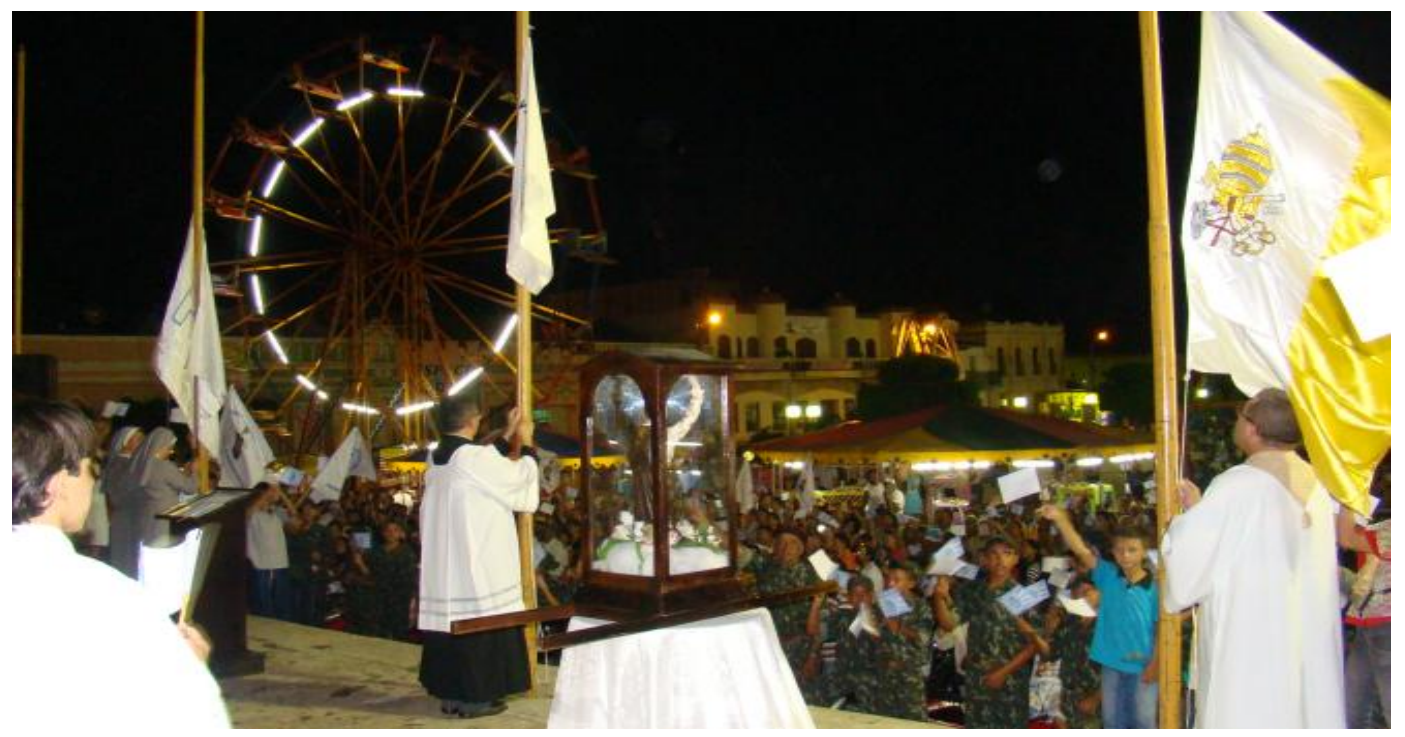

Figura 2: Coroação de São Vicente Ferrer - Festa popular

Fonte: Comissão pastoral, 2010

Segundo representantes da EMBRATUR (1994), o País está bem representado dentro de um cenário internacional de ecoturismo religioso do mundo. O Brasil, com mais de $80 \%$ de sua população seguidores do Catolicismo, traz inúmeras festividades religiosas que atraem milhares e até milhões de turistas. São festas de Padroeiros, Congados, Folia de Reis, Corpus Christi, Semana Santa, São João e São Pedro, entre outras celebrações.

Além da Padroeira do Brasil, Nossa Senhora Aparecida, que tem como feriado Nacional 12 de outubro, no Ceará se comemoram, em maior instância: São José, 19 de março, Padroeiro do Ceará; São Francisco das Chagas, símbolo da fé nordestina, em Canindé-CE, 24 de setembro a 04 de outubro, bem como as devoções dos peregrinos e romeiros do Padre Cícero Romão Batista que, na devoção popular, é conhecido como Padre Cícero ou Padim Ciço do Juazeiro do Norte-CE.

Em Lavras da Mangabeira, entre outras localidades que se mobilizam e celebram a devoção a Pe. Cícero e aos seus padroeiros, comemora-se a Festa do Patriarca São Vicente Ferrer, 05 de abril, em diferenças populacionais em relação aos citados anteriormente, com grande fluxo de fiéis à cidade, em busca das peregrinações e espiritualidades. 


\section{Propostas de Ecoturismo Rural}

Há muito que ser descoberto e proclamado, em Lavras da Mangabeira, pois, além do Boqueirão e das obras faraônicas em torno dele, a demanda gerada pelo turismo incentiva o "mapeamento de trilhas" pelos campos e serras, alcançando pontos, até então, pouco conhecidos e visitados. Chegar até eles é reviver um pouco a sensação dos antigos bandeirantes. De repente surgem, entre essas andanças, depoimentos e deslumbrantes majestosas histórias de coronéis, cangaceiros, parteiras, vaqueiros, mãe de leite, como as das proles poderosas e valentes que administraram os poderes públicos, nos primórdios da narração dos fatos notáveis, ocorridos na vida das pessoas do nosso município.

Princípios que nortearam e remontam aos clãs genealógicos das raízes e bases lavrenses, características perfeitas dos latifúndios cearenses, mapeando com exatidão o perfil de famílias enérgicas e valentes que administraram os poderes públicos como bem queriam, intransigentes em impor normas para estabelecer seus próprios pensamentos, permanecendo ainda, bem como transmitidas por via oral aos descendentes e munícipes:

a) Sinhá D’Amora, a primeira mulher nobre das Artes Plásticas, pintora de boa reputação artística, no cenário brasileiro;

b) A matriarca Fideralina Augusto, sua antecedente, mulher intransigente em seus atos e deliberações, no que diz respeito aos pontos fundamentais e indiscutíveis do passado;

c) Histórias de pessoas com atitudes incomuns: alguém da família Caldas que, por opinião própria, deixou de tomar café, no município, por não ter sido confiada uma quarta (1/4) deste por um comerciante, e passou a andar de sapato, pelo resto de sua vida, para mostrar ao futuro sogro que não era aquilo que ele imaginava que fosse o seu futuro genro, isto é, no seu dizer (dizer do sogro), a filha não deveria casar-se com ele, pois não poderia comprar sequer um sapato para si, quanto mais manter (o genro) uma casa e seus apetrechos domésticos;

d) As histórias versadas pelos inúmeros poetas correligionários, todos oriundos do entorno Boqueirão.

A antiguidade, extensão e formação geológica do município $\left(947,957 \mathrm{~km}^{2}\right)$ com seus monumentos favorecem a existência de fazendas (Sítios) com grutas, olho d'água, cavernas, barragens como Rosário, entre outros, inclusive, lugares privilegiados para os aventureiros compartilhar e curtir os momentos de lazer com sua família, o que requer levantamentos técnicos por profissionais, visando sua possível abertura à visitação pública. Pois no Brasil e em todo o mundo, o turismo ecológico ou ecoturismo está em crescimento progressivo, com um número cada vez maior de adeptos e de lugares onde se possa "aproveitar" as maravilhas da natureza, desde que seja oferecida estrutura logística adequada.

Portanto, quais são as atividades mais procuradas pelos ecoturistas rurais? Esta é uma pergunta que o empreendedor deve ter sempre em mente e que, para manter-se sempre à frente das necessidades de seus visitantes ou hóspedes, deve estar sempre atento ao feed back, ou seja, às informações recebidas de seus clientes. Podemos citar, entre outras, como atividades a serem desenvolvidas em um local destinado ao turismo ecológico: - caminhadas e trilhas rurais; - nado em rios e lagos; - escaladas; - passeios a cavalo e de charretes; - passeios de bondes;- canoagem e pesque-pague;- "tour" por instalações rurais como currais, pastos, locais de ordenha, plantações, etc. 
O que deve ser priorizado, sempre, pelo empreendedor do ecoturismo rural são a qualidade do atendimento e a segurança a ser dada aos hóspedes. Portanto, os funcionários devem ser qualificados, precisam conhecer bem seus afazeres, ser, de preferência, nativos do local e devem possuir um nível cultural adequado.

Oportunidades para esse tipo de atividade estão disponíveis em todas as regiões do Brasil, até mesmo em localidades próximas às grandes capitais e, finalmente, aqui vai o maior de todos os conselhos para os futuros ecoturistas: nunca se esqueçam de que são "visitas" na casa da mãe natureza e que, como bons filhos e educados convidados, não devem sujar nem destruir nada, pois essa é a casa de todos nós. As estatísticas demonstram-nos que, no Brasil, são mais de 12 mil propriedades rurais que geram cerca de 500 mil empregos diretos ou indiretos, dos quais 35\% são representados por mão-de-obra familiar e outros $65 \%$ por pessoas de origem local ou regional.

\section{Perspectivas de Ecoturismo para o Boqueirão de Lavras}

A comunidade de Lavras da Mangabeira anseia pela unidade de conservação (UC) e preservação ambiental, o Boqueirão, enaltecido por Gonçalves (1985) no livro "Universos" (poesias), quando assim se reporta: o seu fenótipo é uma obra sublime do criador. E acrescenta que sua beleza incólume à perfeição etérea de água, pedra e brilho. Pois é, realmente, um fenômeno natural: uma "garganta aberta", 109,92, (cento e nove, noventa e dois) $\mathrm{m}$ em relação ao espelho d'água com a parede rente ao leito do Rio Salgado, por 43,97 (quarenta e três, noventa e sete) $\mathrm{m}$ de largura (SOUZA, 2010), tamanhos potenciais turísticos, poço permanente, se constituindo em uma das mais lindas paisagens da natureza.

O Boqueirão é uma exuberante obra que a natureza criou, geologicamente explicada pela abertura de uma única rocha, provavelmente no período cretáceo inferior. Sua formação rochosa, por sua vez, é composta basicamente por folheiros cristalinos, depressões sertanejas, solos litólicos, vez que a vegetação consolida-se como matagaleria e caatinga. Em busca da diversificação da área, carência e necessidade de estudos sobre a flora e fauna do ecossistema, Calisto Júnior (2007), mestre em Ciências Florestais e Ambientais (PPGCF) UFCG, Patos - PB, vem realizando um incansável levantamento florístico-fitossociológico em um remanescente de caatinga na Serra do Boqueirão, com área de estudo: Serra do Boqueirão, Município Lavras da Mangabeira, Sul do Estado do Ceará.

Na pesquisa acima referida, já foram registrados 1.358 indivíduos pertencentes a 20 famílias, 34 gêneros e 56 espécies. As famílias mais representativas foram: Caesalpiniaceae (11), Euphorbiaceae e Mimosaceae (7), Apocynaceae e Anacardiaceae (4). As espécies características, ocorrentes na área de estudos, e densidade total registrada foram de 2.421 indivíduos ha ${ }^{-1}$, a área basal total, $28,16 \mathrm{~m}^{2} \mathrm{ha}^{-1} \mathrm{e}$ diâmetro máximo e altura registrada, $58 \mathrm{~cm}$ e $11 \mathrm{~m}$, respectivamente.

Dos indivíduos amostrados 42,3\% apresentaram diâmetros entre 3 e $6 \mathrm{~cm}$. Em termos fisionômicos, foi constatado que a área estudada apresenta composição florística variada e, mesmo apresentando locais antropisados, encontra-se em processo de sucessão intermediário, tendendo para um estágio mais avançado de sucessão. 


\section{Considerações finais}

Diante do exposto, se observa uma alternância de insatisfação entre o que é de direito e o que se pode manipular, pois as autoridades consultadas se julgam competentes, inclusive firmando parcerias. Contudo, o abismo se prolonga quanto às propostas e o concreto, quanto à (in)responsabilidade se aproxima. Portanto, constatou-se que o público analisado precisa de orientação administrativa convincente, para cumprir com desígnio a legislação pertinente, pois foi necessário priorizar diversos movimentos comunitários, para minimizar e envolver, em parte, os atores secundários (o homem) na construção do processo.

A população reivindica a "unidade protetora da Área", as autoridades são favoráveis, mas existe um espaço inatingível, intocado, até certo ponto, das reivindicações. E por que essas lacunas ocorrem? Os principais atores nesse campo referem-se à esfera político-partidária. Além da incompetência desses, temem desforra por parte do curral eleitoreiro. Por isso, delegam à população, por mais precária que se processe, bem indispensável à sua produção, vez que o futuro poderá testemunhar perca irrecuperável com relação à preservação do ecossistema até então pleiteado.

\section{Referências}

ALMEIDA, C. R. S., PENA-VEGA, A. e PETRAGLIA I. (Orgs.). Edgar Morim: Ética, Cultura e Educação. $3^{\mathbf{a}}$ ed. São Paulo: Cortez, 2008.

CALIXTO JÚNIOR, J. T.. Levantamento da Composição Florística da Vegetação de Caatinga na Serra do Boqueirão, Lavras da Mangabeira-CE. Anais da XXX Reunião Nordestina de Botânica, Crato-CE, 2007.

CAMPOS, Â. M. N. Bacharel em Turismo (UFPA), Pós-Graduado Docência e Metodologia de Pesquisa em Turismo (UFPA, 2004) e Professor do Curso de Turismo e Hospitalidade do CEFET/PA, 2005.

CEARÁ. Disponível em: < www.ceará.gov.br.ceara/municípioscearenses/detalhamento/ muni... >. Acesso em: 19 mar. 2010.

COSTA, F. L. Plano de Ação da Bacia Cultural do Araripe para o Desenvolvimento Regional. SECULT, Fortaleza, 2006.

FERREIRA, A. B. H. (Cord.). Miniaurélio, Século XXI Escolar: O ministério da língua portuguesa. $4^{\mathrm{a}}$ Ed.

Nova Fronteira: FNDE/PNLD, Rio de Janeiro, 2001.

GONÇAlVES, A. A. Universos. Poesias. Imprensa Oficial do Ceará, Fortaleza, 1985.

LAGE, B. H G. e MilOnE, P. C. (Org.) Turismo: Teoria e Prática. São Paulo: Atlas, 2004. (Org.) Turismo: Teoria e Prática. São Paulo: Atlas, 2000.

Lei $\mathrm{N}^{\mathrm{o}}$ 015/02, 15 de maio de 2002. O prefeito municipal cria, no âmbito do município, Agendo 21 local, a Secretaria do Meio Ambiente de Lavras da Mangabeira-CE, 17 de maio de 2002.

Lei Orgânica do Município. Dentro dos princípios democráticos, 04 de abril de 1990, Lavras da MangabeiraCeará, 1990.

LIMA, L. C. Na terra do Boqueirão. Gráfica Ideal, Lavras da Mangabeira-CE, 1998.

PAIVA, M. P. Uma Matriarca do Sertão: Fideralina Augusto Lima (1832 - 1919). Edições Livro Técnico, Fortaleza-CE, 2008. 
Portal Educação - Programa de Educação Continuada a Distância - EAD - Educação a Distância: parceria entre Portal Educação e Sites Associados. WWW.portaleducação.com.br, 2010.

Projeto de Lei 012/2009, № 12, 20 de maio de 2009. A Câmara de Lavras da Mangabeira-CE dispõe sobre a Política Municipal de Educação Ambiental e dá outras providências, 2009.

ROCHA, M. I. Análise da Oferta e Demanda Turística no Município de Santana do Cariri-CE, CratoCE, 2004.

SOUZA, F. de A. A. e CUNHA, J. C. F. Técnico Agrícola: Topografia/Cadista - CREA: 1666-DT, 2010.

\section{Sobre os Autores:}

(1) Victor Emídio Campos é Licenciado em História e Ciências Biológicas, com Especialização em História do Brasil e em Educação Ambiental pela Universidade Regional do Cariri - URCA. Mestrando em Ciências da Educação pela Universidade San Carlos.

E-mail: victoraltha@ hotmail.com

(2) Cícera Cecília Esmeraldo Alves é Professora da Universidade Regional do Cariri - URCA.

(3) Thalita Ferreira Campos, Bacharel em Biologia e Pós-graduada em Educação Ambiental pela Universidade Regional do Cariri - URCA.

E-mail.:thalitaf_campos@hotmail.com.

Como citar este artigo (Formato ISO):

CAMPOS, V.E.; ALVES, C.C.E.; CAMPOS, T.F. Perspectivas de ecoturismo para o Boqueirão de Lavras da Mangabeira-CE. Id on Line Revista de Psicologia, Julho de 2011, vol.1, no.14, p.36-49. ISSN 1981-1189. 